\title{
Self heat generating synthesis of tri-colour lamp phosphors
}

\author{
C P JOSHI and S V MOHARIL* \\ Department of Physics, Nagpur University, Nagpur 440010, India \\ MS received 23 October 1996; revised 15 April 1997
}

\begin{abstract}
The simple method for the preparation of phosphors such as aluminates, $\mathrm{Y}_{2} \mathrm{O}_{3}$, $\mathrm{YVO}_{4}$ and $\mathrm{LaPO}_{4}$ by the combustion synthesis described earlier in the literature is reported. It is shown here that the phosphors prepared by such synthesis do not possess all the required characteristics. Suitable modifications by way of annealing at $>1200^{\circ} \mathrm{C}$ in controlled atmospheres, however, can yield the phosphors with characteristics which may fulfil the demands of lamp industry.
\end{abstract}

Keywords. Photoluminescence; phosphors; tri-colour lamps; aluminates; rare earth spectra.

\section{Introduction}

Photoluminescent materials are used in $\mathrm{Hg}$-discharge lamps for converting UV light to visible. Such phosphors have been popularly called as 'lamp phosphors'. In 1971, a lamp with high colour rendition index was proposed which was based on blend of phosphors emitting in three primary colour regions (Koedam and Opstelten 1971). Verstegen et al (1974) had demonstrated such lamps for the first time. These lamps have been called tri-colour lamps. Various phosphors used in tri-colour lamps have often been reviewed (Ryan 1981; Pappalardo 1987; Smets 1987, 1991; Welker 1991; Blasse 1995; Ronda 1995). In recent years, some papers have appeared on preparation of these phosphors using self heat generating synthesis, also termed as the combustion synthesis (Ekambaram and Patil 1995 a,b,c; Kingsley et al 1990a,b). Phosphors in fine particle (of the order of several microns) form could be prepared by this method. In order to find out the suitability of the phosphors prepared by this method, it is necessary to study the parameters such as excitation and emission spectra, quantum efficiency, quenching temperature, etc. However, these important properties have not been reported. We have prepared some commonly used phosphors by the combustion synthesis and obtained relevant parameters. These results, which could be of real utility to the lamp industry, are presented in this paper.

\section{Experimental}

The following lamp phosphors were prepared using the combustion synthesis: $\mathrm{YVO}_{4}: \mathrm{Eu}^{3+}$ and $\mathrm{Y}_{2} \mathrm{O}_{3}: \mathrm{Eu}^{3+}$ (red), $\mathrm{BaMgAl}_{10} \mathrm{O}_{17}: \mathrm{Eu}^{2+}, \mathrm{Sr}_{4} \mathrm{Al}_{14} \mathrm{O}_{25}: \mathrm{Eu}^{2+}$ (blue), $\mathrm{Sr}_{5} \mathrm{Eu}_{0.5}^{2+} \mathrm{Mg}_{6} \mathrm{Al}_{55} \mathrm{O}_{94}$ (blue), $\mathrm{CeMgAl}_{11} \mathrm{O}_{19}: \mathrm{Tb}, \quad \mathrm{LaPO}_{4}: \mathrm{Ce}, \mathrm{Tb}$ (green), and $\mathrm{YVO}_{4}$ :Dy (white). The synthesis involved heating of metal nitrates with fuels such as urea at temperatures around $500^{\circ} \mathrm{C}$. The details can be found in the original papers (Kingsley et al 1990a,b; Ekambaram and Patil 1995a,b,c). The compounds so prepared were identified using XRD technique. PL characteristics were studied using Hitachi

\footnotetext{
*Author for correspondence
} 
F-4000 spectrofluorometer. Quantum efficiencies were obtained on a set up described elsewhere (Alexander et al 1993), or by comparing the light output with the standard phosphors.

\section{Results and discussion}

All the phosphors prepared were in fine particle form. The particle size $(<7 \mu)$, which was determined using Malvern particle size anaiyser, is suitable for lamps.

Figure 1 shows the $\mathrm{PL}$ spectra for $\mathrm{Sr}_{4} \mathrm{Al}_{14} \mathrm{O}_{25}: \mathrm{Eu}^{2+}$ phosphor. Emission is obtained around $438 \mathrm{~nm}$ and the excitation maximum is observed at $318 \mathrm{~nm}$. This is not characteristic of $\mathrm{Sr}_{4} \mathrm{Al}_{14} \mathrm{O}_{25}: \mathrm{Eu}^{2+}$. Most probably, another phase is formed. We modified the synthesis so as to produce reducing atmosphere. The phosphor prepared with this synthesis exhibited the well known (Smets et al 1989) emission in the form of a dominant band around $480 \mathrm{~nm}$ and a weak one around $400 \mathrm{~nm}$. The excitation spectrum consists of two bands around $270 \mathrm{~nm}$ and $350 \mathrm{~nm}$. The emission, however was very weak, about 25 times weaker than that required for lamp application. We prepared other Sr-aluminate phases. In $\mathrm{SrAl}_{12} \mathrm{O}_{19}: \mathrm{Eu}^{2+}$ emission was observed around $390 \mathrm{~nm}$ which agrees with the reported value (Kutty et al 1990). However, the quantum efficiency was much below the reported efficiencies of the order of $90 \%$ (Stevels and Schrama-de Pauw 1976; Kutty et al 1990). The aluminate $\mathrm{Sr}_{5} \mathrm{Eu}_{0.5}^{2+} \mathrm{Mg}_{6}$ $\mathrm{Al}_{55} \mathrm{O}_{94}$ was also prepared. Emission in this phosphor was obtained around $463 \mathrm{~nm}$,

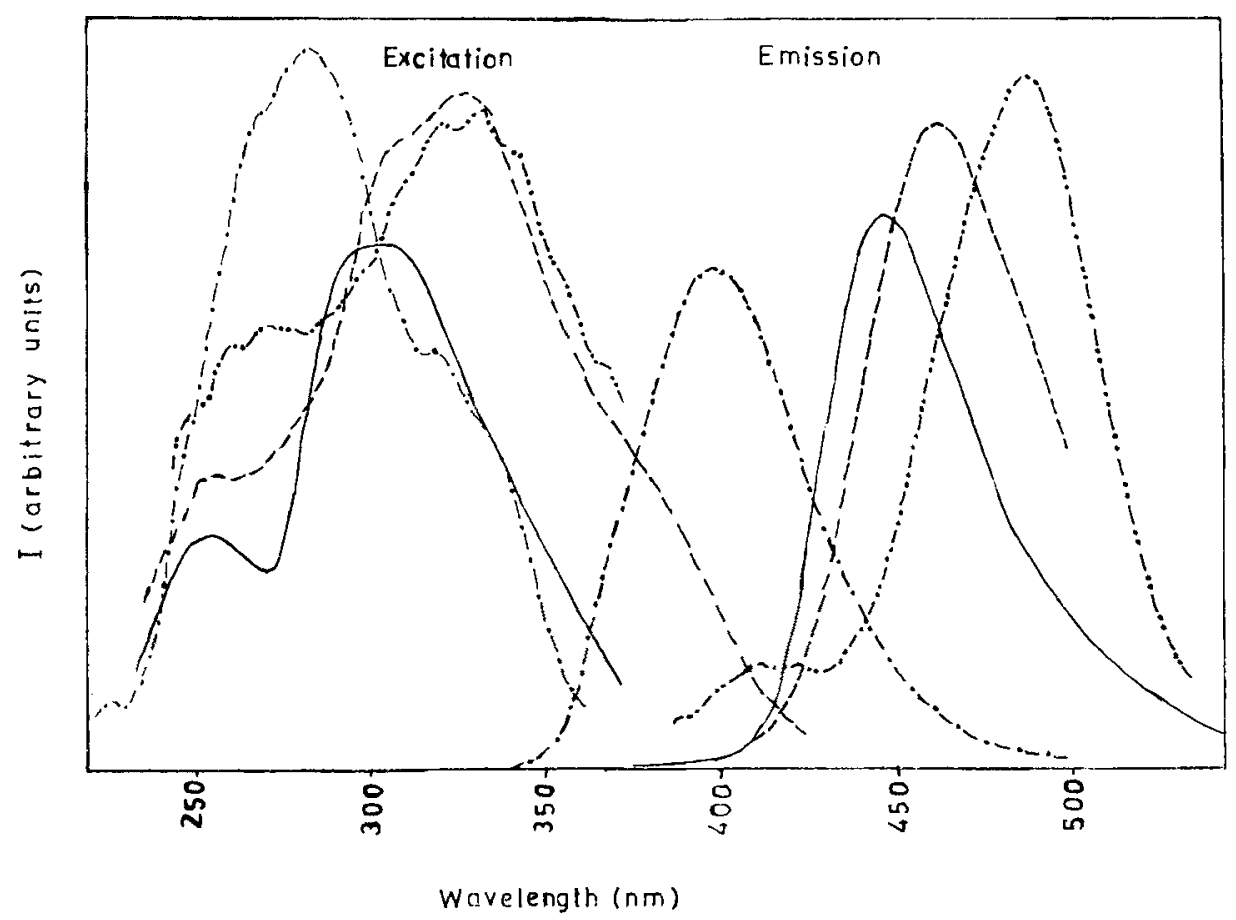

Figure 1. PL spectra for various europium doped $\mathrm{Sr}$-aluminates (-.-.--, $\mathrm{SrAl}_{12} \mathrm{O}_{19}$; $\mathrm{Sr}_{4} \mathrm{Al}_{14} \mathrm{O}_{25}: \mathrm{Eu} ;-\ldots-. .-, \mathrm{Sr}_{4} \mathrm{Al}_{14} \mathrm{O}_{25}: \mathrm{Eu}$ (prepared under reducing condition); - - -, $\left.\mathrm{Sr}_{5} \mathrm{Eu}_{0 \cdot 5} \mathrm{Mg}_{6} \mathrm{Al}_{55} \mathrm{O}_{94}: \mathrm{Eu}\right)$. 
which was close to the reported value (Verstegen 1974). The quantum efficiency (at $254 \mathrm{~nm}$ ) was around $25 \%$ only. The excitation spectrum consisted of a strong maximum at $331 \mathrm{~nm}$ and only a weaker band around $250 \mathrm{~nm}$. Thus, it can be concluded that by starting with different $\mathrm{Sr}$ : Al ratio, various $\mathrm{Sr}$-aluminates can be prepared by the combustion synthesis. However, quantum efficiencies of the samples prepared by the combustion synthesis are an order of magnitude lower than those reported for the compounds. Perhaps, full reduction of Eu to the divalent form is not achieved. The temperature attained during the combustion synthesis may not be high enough to yield the phosphors with adequate PL efficiencies.

Figure 2 shows the $\mathrm{PL}$ spectra for $\mathrm{BaMgAl}_{10} \mathrm{O}_{17}: \mathrm{Eu}^{2+}$. Intense emission is observed around $450 \mathrm{~nm}$. Quantum efficiency is quite high, around $90 \%$.

Figure 2 also includes PL spectra for $\mathrm{CeMgAl}_{11} \mathrm{O}_{19}$ : Tb phosphor. This phosphor had yellow body colour. Most probably, this occurs due to presence of small amount of tetravalent $\mathrm{Ce}$ and $\mathrm{Tb}$ ions. Due to strong self-absorption, the apparent quantum efficiency of the phosphor was only $40 \%$. We modified the synthesis so as to produce the phosphor with white body colour with quantum efficiency above $90 \%$. The modified process is based on preparing the sample under reducing atmosphere. The excitation spectrum has a broad maximum around $270 \mathrm{~nm}$, and the overlap with $\mathrm{Hg}$ emission at $253.7 \mathrm{~nm}$ is satisfactory. Another well known green emitting phosphor $\mathrm{LaPO}_{4}$ : Ce, Tb was also prepared by the combustion synthesis. Again, the

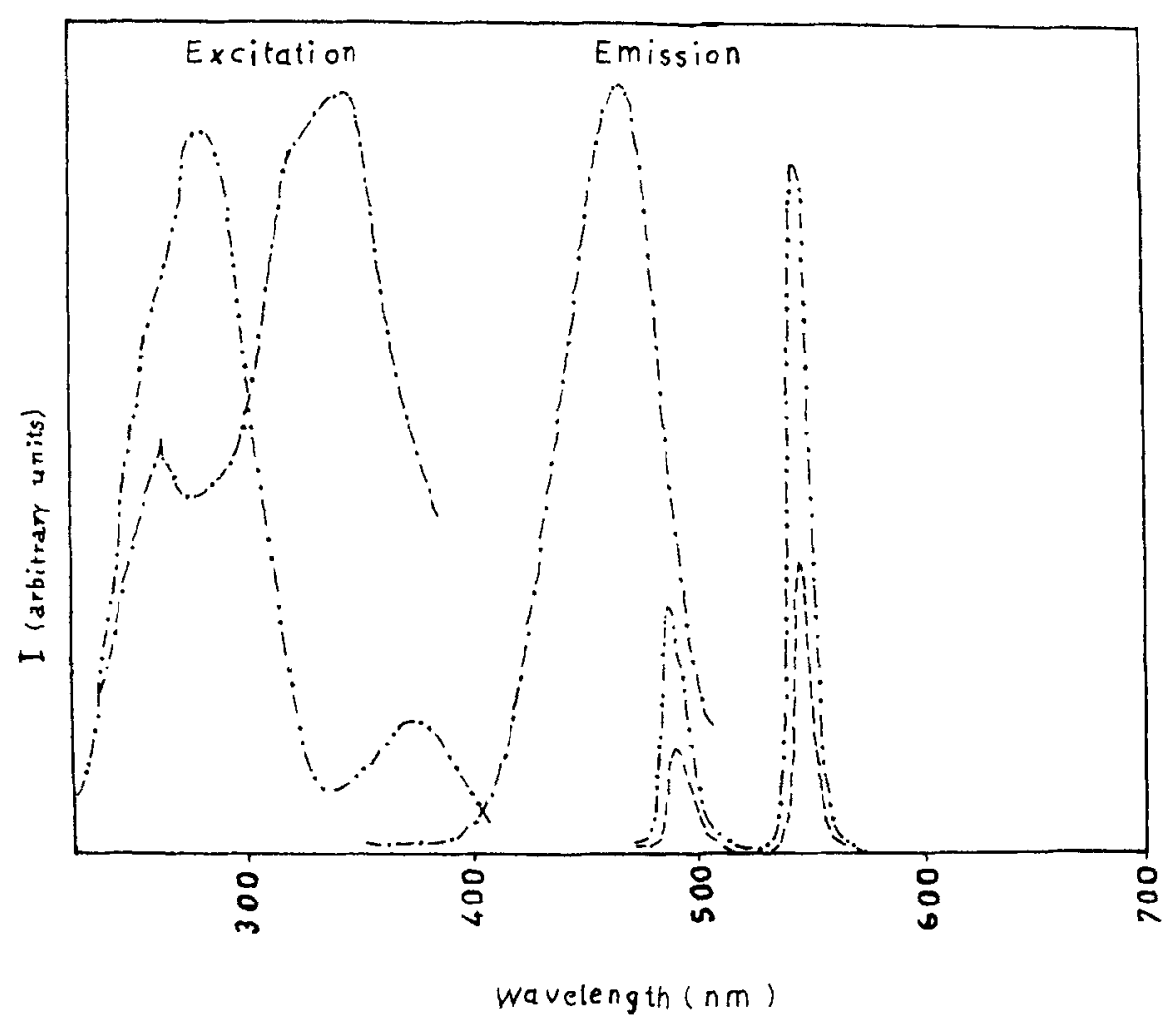

Figure 2. PL spectra for some commonly used lamp phosphors prepared by combustion synthesis $\left(---, \mathrm{LaPO}_{4}: \mathrm{Ce}, \mathrm{Tb} ;-. .-\ldots,(\mathrm{Ce}, \mathrm{Tb}) \mathrm{MgAl}_{11} \mathrm{O}_{19} ;-. .,-, \mathrm{BaMgAl}_{10} \mathrm{O}_{17}: \mathrm{Eu}\right)$. 


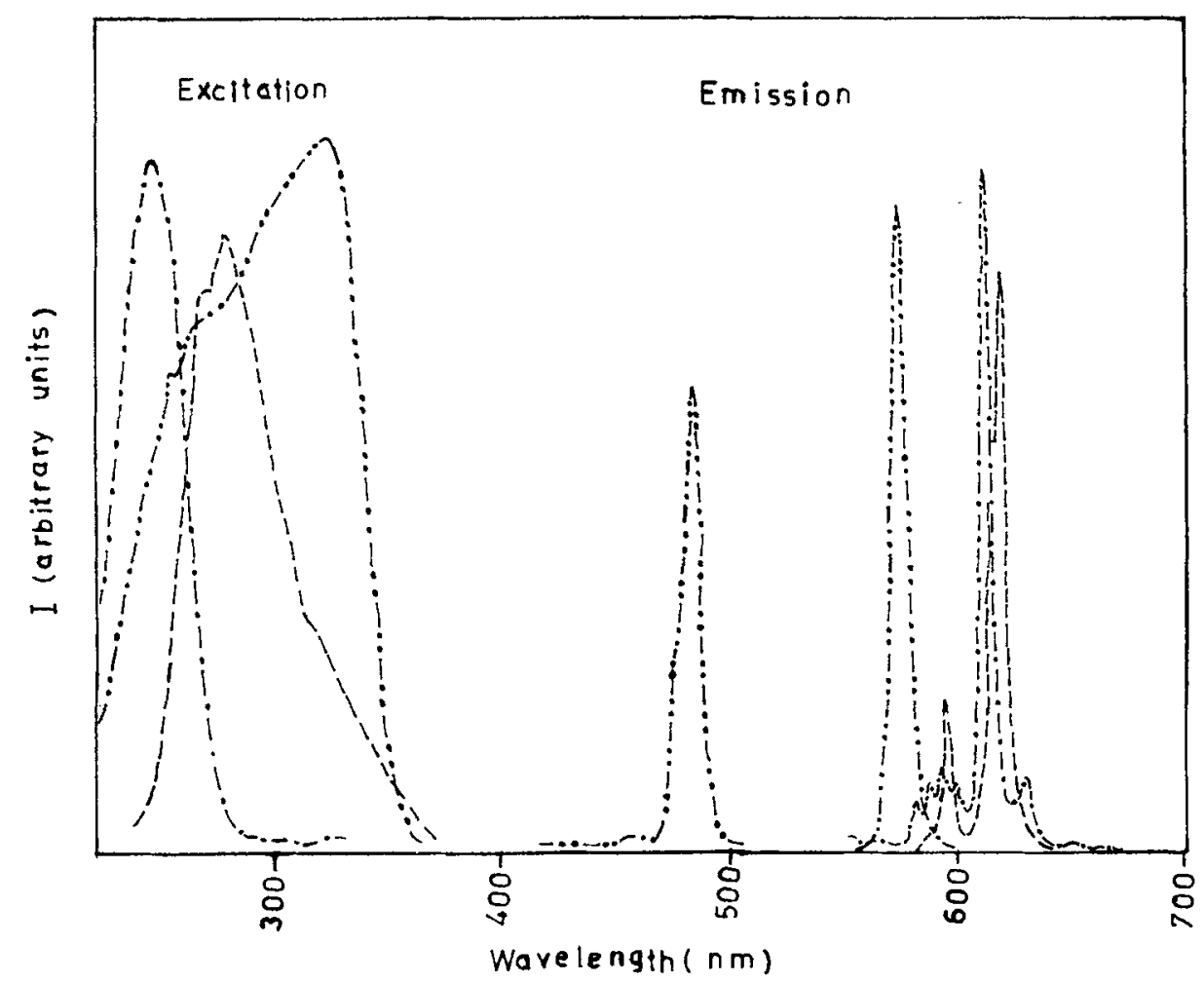

Figure 3. $\mathrm{PL}$ spectra for some yttrium based phosphors $\left(.--,, \mathrm{Y}_{2} \mathrm{O}_{3}: \mathrm{Eu} ;-. .-. .-, \mathrm{YVO}_{4}:\right.$ Dy; -. $-\mathrm{YVO}_{4}: \mathrm{Eu}$ ).

usual combustion synthesis produced a phosphor with yellow body colour. The modified synthesis involving reheating in reduced atmosphere produced the phosphor with desired properties.

Figure 3 shows PL spectra for $\mathrm{Eu}^{3+}$ doped $\mathrm{Y}_{2} \mathrm{O}_{3}$ and $\mathrm{YVO}_{4}$ and Dy doped $\mathrm{YVO}_{4}$ phosphors. In the case of the former, the well known emission around $610 \mathrm{~nm}$ is observed. The excitation peaking at $243 \mathrm{~nm}$ overlaps well with the $\mathrm{Hg}$ emission. However, the light output was only $40 \%$, of that for the commercial phosphor for which $100 \%$ quantum efficiency is reported for (Welker 1991). When the $\mathrm{Y}_{2} \mathrm{O}_{3}$ : Eu phosphor prepared by the combustion synthesis was re-annealed at $1400^{\circ} \mathrm{C}$ for $1 \mathrm{~h}$, efficiencies approaching $100 \%$ were obtained. It seems, that quenching the sample from high temperature phase occurring above $1400^{\circ} \mathrm{C}$ is a must for obtaining good quantum efficiency (Schaik and Blasse 1992). Future attempts should be directed at achieving such temperatures during the combustion synthesis e.g. by using additional oxidizer (Gopichandran and Patil 1990). It is known that the temperature attained during the combustion synthesis is well in excess of the initiating temperature. The temperature can be controlled by choice and the quantity of the fuel and oxidizer (Chick et al 1990; Kingsley and Pederson 1993).

$\mathrm{YVO}_{4}: \mathrm{Eu}$ and $\mathrm{YVO}_{4}$ : Dy phosphors prepared by combustion synthesis had a yellow body colour. These phosphors had to be re-heated at temperatures around $1200{ }^{\circ} \mathrm{C}$ for removing the body colour. High quantum efficiency of the order of $90 \%$ 
was then observed for both the phosphors. $\mathrm{YVO}_{4}$ : Eu emission is in the form of narrow lines around 595 and $616 \mathrm{~nm}$ in the orange red region of the spectrum corresponding to transitions ${ }^{5} D_{0} \rightarrow{ }^{7} F_{1},{ }^{7} F_{2}$. YVO ${ }_{4}$ : Dy emission is white, consisting of yellow $(573 \mathrm{~nm})$ and blue $(483 \mathrm{~nm})$ bands corresponding to ${ }^{4} F_{9 / 2} \rightarrow{ }^{6} H_{13 / 2}$ and ${ }^{6} H_{15 / 2}$ transitions.

\section{Conclusions}

Lamp phosphors in fine particle form were obtained by the combustion synthesis. However, the quantum efficiencies, body colour, excitation spectrum, etc of the phosphors obtained by the method described in the literature are not suitable for application in lamps. Some modifications, such as reheating in the reducing atmosphere, of the synthesis, however, seem to be possible. These modified methods can lead to synthesis of phosphors with characteristics acceptable to lamp industry. Future efforts may be directed towards achieving these modifications.

\section{Acknowledgement}

We are grateful to Dr G Alexander, Bhabha Atomic Research Centre, Bombay for carrying out quantum efficiency measurements.

\section{References}

Alexander G, Ramakrishna P. Mukherjee T K and Nambi K S V 1993 Indian J. Pure Appl. Phys. 31531 Blasse G 1995 J. Alloy Comp. 225529

Chick L A, Pederson L R, Maupin G D, Bates J L, Thomas L F and Exarhos G J 1990 Mater. Letts 106

Ekambaram S and Patil K C 1995a J. Alloy Comp. 217104

Ekambaram S and Patil K C 1995b J. Mater. Chem. 5905

Ekambaram S and Patil K C 1995c Bull. Mater. Sci. 18921

Gopichandran K and Patil K C 1990 Mater. Letts 10291

Kingsley J J and Pederson L R 1993 Mater. Letts 1889

Kingsley J J, Suresh K and Patil K C 1990a J. Mater. Sci. 251305

Kingsley J J, Manickam N and Patil K C 1990b Bull. Mater. Sci. 13179

Koedam M and Opstelten J J 1971 Light Res. Tech. 3205

Kutty T R N, Jagannathan R and Rao R P 1990 Mater. Res. Bull. 251355

Pappalardo R G 1987 in Spectroscopy of solid state laser type materials (ed.) Di Bartolo (New York: Plenum Press) pp 397-429

Ronda C R 1995 J. Alloy Comp. 225534

Ryan F M 1981 J. Lum. 24/25 827

Schaik V W and Blasse G 1992 Chem. Mater, 4410

Smets B M J 1987 Mater. Chem. Phys. 16283

Smets B M J 1991 in Adv. non-radiative processes in solids (ed.) Di Bartolo (New York: Plenum Press) pp $353-386$

Smets B M J. Ratlen J, Hoeks G and Verlijsdonk 1989 J. Electrochem. Soc. 1362119

Stevels A L N and Schrama-de Pauw A D P 1976 J. Electrochem. Soc. 123691

Verstegen J M P J 1974 J. Electrochem. Soc. 1211623

Verstegen J M P J, Radielovic D and Vrenken L E 1974 J. Electrochem. Soc. 1211627

Welker T 1991 J. Lum. $48 / 4949$ 